\title{
Focal Segmental Glomerulosclerosis, Not Otherwise Specified
}

National Cancer Institute

\section{Source}

National Cancer Institute. Focal Segmental Glomerulosclerosis, Not Otherwise Specified. NCI Thesaurus. Code C123139.

Segmental scarring of the glomerulus, which may result in isolated proteinuria or nephrotic syndrome, which affects only part of the glomerulus and only some of the glomeruli. Additionally, the Not Otherwise Specified classification excludes FSGS tip, perihilar, collapsing, and cellular variants. (D'Agati VD, et al. "Pathologic Classification of Focal Segmental Glomerulosclerosis: A Working Proposal." Am J Kidney Dis 43.2 (2004): 368-82.) 